\title{
Molecular epidemiology of methicillin-susceptible Staphylococcus aureus (MSSA) isolated from milk of cows with subclinical mastitis
}

\author{
E.C.R. Bonsaglia ${ }^{a}, *$, N.C.C. Silva ${ }^{b}$, B.F. Rossi ${ }^{a}$, C.H. Camargo ${ }^{c}$, S.T.A. Dantas ${ }^{a}$, H. Langoni ${ }^{d}$, \\ F.F. Guimarães ${ }^{\mathrm{d}}$, F.S. Lima ${ }^{\mathrm{e}}$, J.R. Fitzgerald ${ }^{\mathrm{f}}$, A. Fernandes Júnior ${ }^{\mathrm{a}}$, V.L.M. Rall ${ }^{\mathrm{a}, * *}$ \\ a Department of Microbiology and Immunology, Institute of Bioscience, São Paulo State University (UNESP), Botucatu, SP, 18618-689, Brazil \\ ${ }^{\mathrm{b}}$ Department of Food Science, Faculty of Food Engineering (FEA), University of Campinas (UNICAMP), Campinas, SP, 13083-862, Brazil \\ ${ }^{c}$ Adolfo Lutz Institute, São Paulo, SP, 01246-000, Brazil \\ d Department of Hygiene Veterinary and Public Health, Sao Paulo State University Botucatu-SP, 18618-689, Brazil \\ e Department of Veterinary Clinical Medicine, University of Illinois, Urbana-Champaign, IL, 61802, USA \\ ${ }^{\mathrm{f}}$ The Roslin Institute and Edinburgh Infectious Diseases, University of Edinburgh, Easter Bush, Midlothian, United Kingdom
}

\section{A B S T R A C T}

Bovine mastitis has been a concern for dairy herd for decades. The adaptation capacity of one of the main species responsible for this disease, Staphylococcus aureus (S. aureus), plays a pivotal role in this issue. The aim of this study was to establish a molecular and phenotypic profile of $285 \mathrm{~S}$. aureus strains isolated from milk of subclinical mastitis cows from 18 different farms in São Paulo State using spa typing, multilocus sequence typing (MLST), pulsed field gel electrophoresis (PFGE), agr cluster (I, II, III and IV) typing, PCR for genes including enterotoxins (sea, seb, sec, sed, see, seg, seh, sei), toxic shock syndrome toxin (tsst-1), and Panton-Valentine leucocidin (pvl), as well as in vitro resistance assays for 12 antibiotics. The results showed a wide variety of strains with a high toxigenic potential; concomitantly, sec, seg and seh were prevalent. In addition, we observed a predominance of the spa types t605 (ST 126, CC126) and t127 (ST1, CC1) and the unusual presence of t321 causing bovine mastitis, which has been previously reported only in swine. The most frequent ST were ST126 (70.5\%) and ST1 (10.5\%). Regarding PFGE, we observed four major groups and six profile patterns. The highest resistance was observed for streptomycin (9.5\%), followed by tetracycline (3.5\%), clindamycin (9.3\%), and erythromycin (2.8\%). The tsst-1 gene was detected in 36.8\% of isolates and pvl was not observed. One hundred and thirty-six (47.7\%) isolates possessed agr type II, followed by types III (20\%) and I (8.1\%), with type IV not being detected. We observed that the same spa type could result in different PFGE profiles, so the exclusive use of spa type sequences can lead to incorrect interpretations regarding the spread of clones in an epidemiological context.

\section{Introduction}

Staphylococcus aureus is one the most important pathogens causing mastitis [1] and is a public health concern due to the presence of at least one gene encoding for enterotoxin production in most isolates [2]. Also, some of these staphylococcal enterotoxins (SEs) may play an important role in the pathogenesis of mastitis [3], such as toxic shock syndrome toxin-1 (TSST-1) and Panton-Valentine leucocidin (PVL) $[4,5]$.

Resistance to $\beta$-lactam antibiotics has been also reported as one of the main problems related to the persistence of mastitis [6,7]. Multidrug resistance is also reported to be increasing. Wang et al. [8] found that $69 \%$ of the $S$. aureus isolates collected from milk of animals with bovine mastitis were resistant to more than 10 drugs used in the treatment of mastitis.
S. aureus isolates collected from dairy cattle with mastitis have been studied by various molecular methods such as multi locus sequence typing (MLST), pulsed filed gel electrophoresis (PFGE), and agr cluster and spa typing, which allow for the characterization of this pathogen through the comparison of sequences or fragments described in different parts of the world; these techniques can also be used to trace, dispersal routes and demonstrate the global spread of clones $[9,10]$. Many studies have shown that only a few specialized clones are responsible for most cases of mastitis on a single farm and some of these clones may have a wide geographical distribution $[9,11]$.

Due variability and diversity in nucleotide sequences and even in genetic loci, MLST has over 2400 "sequence types" (ST). Most STs are grouped into a limited number of clonal complexes (CCs) which appear to be distributed worldwide. The predominant CCs in S. aureus are CC1, CC5, CC8, CC15, CC22, CC30, CC45, CC59, CC80, CC97, and CC121

\footnotetext{
* Corresponding author. Department of Microbiology and Immunology, Institute of Biosciences, Sao Paulo State University - UNESP, Post Office Box 510, 18618970, Botucatu, Sao Paulo, Brazil.

** Corresponding author. Department of Microbiology and Immunology, Institute of Biosciences, Sao Paulo State University - UNESP, Post Office Box 510, 18618970, Botucatu, Sao Paulo, Brazil.

E-mail addresses: erikabonsaglia@gmail.com (E.C.R. Bonsaglia), vera.rall@unesp.br (V.L.M. Rall).
} 
Table 1

Distribution of virulence genes regarding the molecular characterization of $S$. aureus strains, isolated from the milk of cows with subclinical mastitis.

\begin{tabular}{|c|c|c|c|c|c|c|c|c|c|c|c|c|}
\hline \multirow[t]{2}{*}{ Spa types } & \multirow[t]{2}{*}{$\mathrm{N}$} & \multicolumn{4}{|c|}{ agr types } & \multicolumn{7}{|c|}{ virulence genes } \\
\hline & & agrI & agrII & agrIII & $\operatorname{agrNT}$ & tsst & sea & $\sec$ & sed & seg & seh & sei \\
\hline t605 & 201 & 9 & 125 & 18 & 49 & 73 & 24 & 171 & 9 & 194 & 177 & 28 \\
\hline $\mathrm{t} 127$ & 30 & 0 & 1 & 21 & 8 & 10 & 3 & 22 & 0 & 29 & 26 & 1 \\
\hline $\mathrm{t} 342$ & 7 & 0 & 1 & 6 & 0 & 0 & 0 & 6 & 0 & 7 & 7 & 2 \\
\hline $\mathrm{t} 458$ & 7 & 7 & 0 & 0 & 0 & 7 & 0 & 3 & 0 & 7 & 6 & 2 \\
\hline t693 & 6 & 0 & 5 & 0 & 1 & 1 & 0 & 4 & 0 & 6 & 5 & 1 \\
\hline t521 & 6 & 3 & 0 & 0 & 3 & 4 & 1 & 4 & 1 & 6 & 5 & 2 \\
\hline $\mathrm{t} 318$ & 4 & 0 & 2 & 2 & 0 & 1 & 1 & 2 & 0 & 4 & 3 & 3 \\
\hline $\mathrm{t} 177$ & 3 & 0 & 0 & 2 & 1 & 1 & 0 & 3 & 0 & 3 & 3 & 0 \\
\hline t11659 & 3 & 0 & 0 & 0 & 3 & 0 & 1 & 1 & 0 & 3 & 3 & 0 \\
\hline t002 & 2 & 1 & 1 & 0 & 0 & 2 & 0 & 0 & 0 & 2 & 2 & 2 \\
\hline t021 & 2 & 0 & 0 & 2 & 0 & 0 & 0 & 0 & 0 & 2 & 2 & 0 \\
\hline $\mathrm{t} 2164$ & 2 & 0 & 1 & 0 & 1 & 1 & 1 & 2 & 0 & 2 & 2 & 2 \\
\hline t6811 & 2 & 0 & 0 & 0 & 2 & 0 & 0 & 2 & 0 & 1 & 2 & 0 \\
\hline $\mathrm{t} 114$ & 1 & 0 & 0 & 0 & 1 & 0 & 0 & 1 & 0 & 1 & 1 & 0 \\
\hline t1192 & 1 & 0 & 0 & 1 & 0 & 1 & 0 & 0 & 0 & 1 & 1 & 0 \\
\hline $\mathrm{t} 138$ & 1 & 1 & 0 & 0 & 0 & 0 & 0 & 1 & 0 & 0 & 0 & 0 \\
\hline t2066 & 1 & 0 & 0 & 1 & 0 & 1 & 0 & 1 & 0 & 1 & 0 & 1 \\
\hline t321 & 1 & 0 & 0 & 1 & 0 & 0 & 0 & 0 & 0 & 1 & 1 & 0 \\
\hline t3324 & 1 & 0 & 0 & 1 & 0 & 1 & 0 & 0 & 0 & 1 & 1 & 0 \\
\hline $\mathrm{t} 456$ & 1 & 1 & 0 & 0 & 0 & 1 & 0 & 1 & 0 & 1 & 0 & 0 \\
\hline t559 & 1 & 0 & 0 & 1 & 0 & 0 & 0 & 1 & 0 & 1 & 1 & 0 \\
\hline t6980 & 1 & 0 & 0 & 1 & 0 & 0 & 0 & 1 & 0 & 1 & 1 & 0 \\
\hline t7335 & 1 & 1 & 0 & 0 & 0 & 1 & 0 & 1 & 0 & 1 & 1 & 0 \\
\hline total & 285 & 23 & 136 & 57 & 69 & 105 & 31 & 227 & 10 & 275 & 250 & 44 \\
\hline
\end{tabular}

NT: not typable.

[12].

Therefore, molecular studies of $S$. aureus isolated from dairy farms can provide information about the dispersion of clones around the world in order to determine which of the most common circulating clones are causing disease.

The aim of the present work was to assess the molecular-epidemiological relationships between MSSA isolated from milk of cows with mastitis through spa typing, MLST, PFGE, and agr typing and to verify the presence of virulence factors and drug resistance.

\section{Materials and methods}

\subsection{Samples}

A total of 4,908 quarter milk samples from 1,313 cows were analyzed, 2,118 samples (43.2\%) were diagnosed as subclinical mastitis, obtained from 18 different dairy farms in São Paulo State, Brazil. Cows with subclinical mastitis presented no physical symptoms, absence of lumps or flakes, and no abnormal color or consistency of milk from the first three or five streams of milk were observed, but samples had high cell counts. The diagnosis of each quarter was based on the California Mastitis Test (CMT), according to Schalm and Noorlander [13], and confirmed by somatic cell counting (SCC), defined as a cow-level SCC above 200,000 cells/mL using flow cytometry (Somacount 300, Bentley Instruments, Chaska, MN). A milk sample from each positive quarter based on the CMT and CCS tests were plated onto blood agar plates (Oxoid Brasil Ltda, São Paulo, Brazil) and incubated at $37^{\circ} \mathrm{C}$ for up to $72 \mathrm{~h}$. The colonies were identified based on morphology, Gram staining, and catalase, coagulase, and DNase activities [14]. Two hundred and eighty-five $S$. aureus isolates $(13.5 \%, \mathrm{n}=285 / 2118)$ were obtained and molecular confirmation was performed using multiplex PCR, looking for a species-specific staphylococcal nuclease (nuc) gene, as well as the staphylococcal methicillin-resistance genetic determinant (mecA) [15].

\subsection{PCR testing for genes encoding staphylococcal virulence factors}

The Minispin Kit (GE Healthcare, Little Chalfont, UK) was used for
DNA extraction according to the manufacturer's instructions. We performed PCR for the detection of staphylococcal super-antigens (Sags) genes [16,17], and lukF/S-PV [18]. S. aureus USA 100 (lukF/S-PV), ATCC 13565 (sea), ATCC 14458 (seb), ATCC 19095 (sec), FRI 361 (sed, seg, sei), ATCC 27664 (see), FRI 137 (seh), and ATCC 51650 (tsst-1) were used as positive controls and ultrapure water was used as the negative control.

\subsection{Molecular typing of $S$. aureus isolates}

All isolates were tested for the spa gene (http://spaserver.ridom.de) and the agr allotype [19]. MLST (http://www.mlst.net) was performed on just one isolate for the more frequent spa type. PFGE of genomic DNA, digested with the macro-restriction SmaI enzyme under standardized Pulsenet electrophoresis conditions, was performed on 10 randomly selected strains, isolated from four different farms. A dendrogram of percentage similarity was calculated to define clonality by PFGE using a similarity value of $80 \%$ as a cut-off, which is considered the gold standard [20]. The band profiles were compared according to Bionumérics (BioNumerics software, 5.0) and Tenover et al. [21].

\subsection{Antimicrobial susceptibility testing and detection of resistance genes}

Antimicrobial susceptibility was performed using the disk-diffusion agar method, according to recommendations of the Clinical and Laboratory Standards Institute (CLSI), [22]. The drugs tested were oxacillin, cefoxitin, tetracycline, erythromycin, clindamycin, gentamicin, tobramycin, streptomycin, trimethoprim-sulfamethoxazole, ciprofloxacin, cephalothin, and vancomycin. The detection of resistance genes was investigated in resistant isolates by PCR, using specific primers such as mecC (cefoxitin and oxacillin), ant(4') (tobramycin), aac (6')-Ie-aph(2")-Ia (gentamicin), aph(3')-IIIa (kanamycin and amikacin), tet $(K)$, tet $(L)$, and $\operatorname{tet}(M)$ (tetracycline), $\operatorname{erm}(A), \operatorname{erm}(B), \operatorname{erm}(C)$, and msrA (erythromycin), and $g r l(A)$ and $g y r(A)$ (ciprofloxacin) [23-30]. Sanger sequencing was performed for the grl $(A)$ and gyr $(A)$ genes. 


\section{Results}

\subsection{Typeability and diversity of spa types}

All 285 strains were confirmed as $S$. aureus using a PCR assay, but none were identified to be MRSA. As can be observed in Table 1, we found 23 different spa types ( $\mathrm{t} 605, \mathrm{t} 127, \mathrm{t} 458, \mathrm{t} 521, \mathrm{t} 342, \mathrm{t} 318, \mathrm{t} 693$, t177, t11659, t021, t2164, t1192, t7335, t114, t6811, t6980, t002, t3324, t559, t138, t321, t456, t2066); the most frequent were t605, occurring in 201 isolates (70.5\%), and t127, found in 30 isolates $(10.5 \%)$.

\subsection{Clonal lineages}

The most frequent ST was ST126, occurring in $70.5 \%$ of isolates, followed by ST1 (10.5\%), belonging to CC 126 and 1, respectively. The Ridom Staph Type software also identified five strains belonging to CC 30 , with the spa types t138 $(\mathrm{n}=1)$ and $\mathrm{t} 318(\mathrm{n}=4)$, and three strains identified as $\mathrm{t} 177$ belonged to CC1.

\subsection{Pulsed field gel electrophoresis (PFGE)}

We performed PFGE on ten strains, randomly selected, with eight being t605/ST126 and two being t693/ST1. The isolates were subdivided into six PFGE patterns, clustered into four dominant PFGE types.

The strains analyzed by PFGE were from four different farms (Fig. 1). According to Tenover et al. [22], only three strains from farm I were closely related with, the patterns showing variations in two to three bands. It is interesting to note that strain 18 was closely related to strain $08(90.2 \%)$ but had a different spa type and MLST, yet the same agr cluster. Equally, strains 128 and 89 were closely related according to PFGE and harbored the same differences but were isolated from different farms. We also observed six unrelated PFGE profiles considering the same spa type on different farms, such as t605.

\section{4. agr cluster typing}

Type II agr was the most frequent, occurring in 136 (47.7\%) out of 285 strains, followed by type III $(n=57,20 \%)$ and type I $(n=23$, $8.1 \%)$. Type IV agr was not found and $69(24.2 \%)$ did not belong any
Table 2

Susceptibility to antimicrobial agents and detection of associated genes in $S$. aureus strains, isolated from milk of cows with subclinical mastitis.

\begin{tabular}{llll}
\hline Antibiotic/gene & Susceptible (N) & Intermediate (N) & Resistant (N) \\
\hline Oxacillin & 285 & 0 & 0 \\
Cefoxitin (mecA, mecC) & 281 & 0 & $4(0 / 0)$ \\
Tetracycline (tetK, tetM, & 275 & 0 & $10(10$ tetK) \\
$\quad$ tetL) & & & 1 (ant $\left.4^{\prime}\right)$ \\
Tobramycin [ant(4')- Ia] & 283 & 1 (ant $\left.4^{\prime}\right)$ & 0 \\
Erythromycin (erm cl, msrA) & 277 & $8(4$ mrsA) & 27 \\
Streptomycin & 258 & 0 & 0 \\
Gentamicina aac(6')-Ie-aph & 285 & 0 & \\
$\quad\left(2^{\prime \prime}\right)-I a$ & & & 9 \\
Clindamycin & 276 & 0 & 1 \\
Trimethoprim- & 284 & 0 & 1 \\
$\quad$ sulfamethoxazole & & & $3(3$ grlA, \\
Cephalothin & 284 & 0 & gyrA) \\
Ciprofloxacin (grlA), gyrA) & 282 & 0 & 0 \\
& & & 0 \\
Vancomycin & 285 & 0 & \\
Kanamicym aph(2") & 285 & 0 &
\end{tabular}

Note: cl: cluster.

group.

\subsection{Virulence factors}

Regarding virulence factors, the tsst-1 gene was found in $36.8 \%$ $(\mathrm{n}=105)$ of isolates. The SE gene distribution was highly variable, since all isolates $(n=285)$ were positive for at least one of these genes. The most frequent were seg, occurring alone or in different combinations in $275(96.5 \%)$ isolates, followed by seh $(\mathrm{n}=250,87.7 \%)$, sec ( $\mathrm{n}=227,79.6 \%)$, sei $(\mathrm{n}=44,15.4 \%)$, sea $(\mathrm{n}=31,10.9 \%)$, and sed ( $n=10,3.5 \%)$. The seb and see genes were not observed, nor was the pvl gene.

\subsection{Antimicrobial susceptibility testing and detection of resistance genes}

As observed in Table 2, streptomycin resistance was the most prevalent $(9.5 \%)$, followed by tetracycline $(3.5 \%)$, clindamycin $(3.2 \%)$, cefoxitin (1.4\%), and ciprofloxacin (1.1\%) resistance. Resistance to cephalothin, trimethoprim, and tobramycin was observed in just one

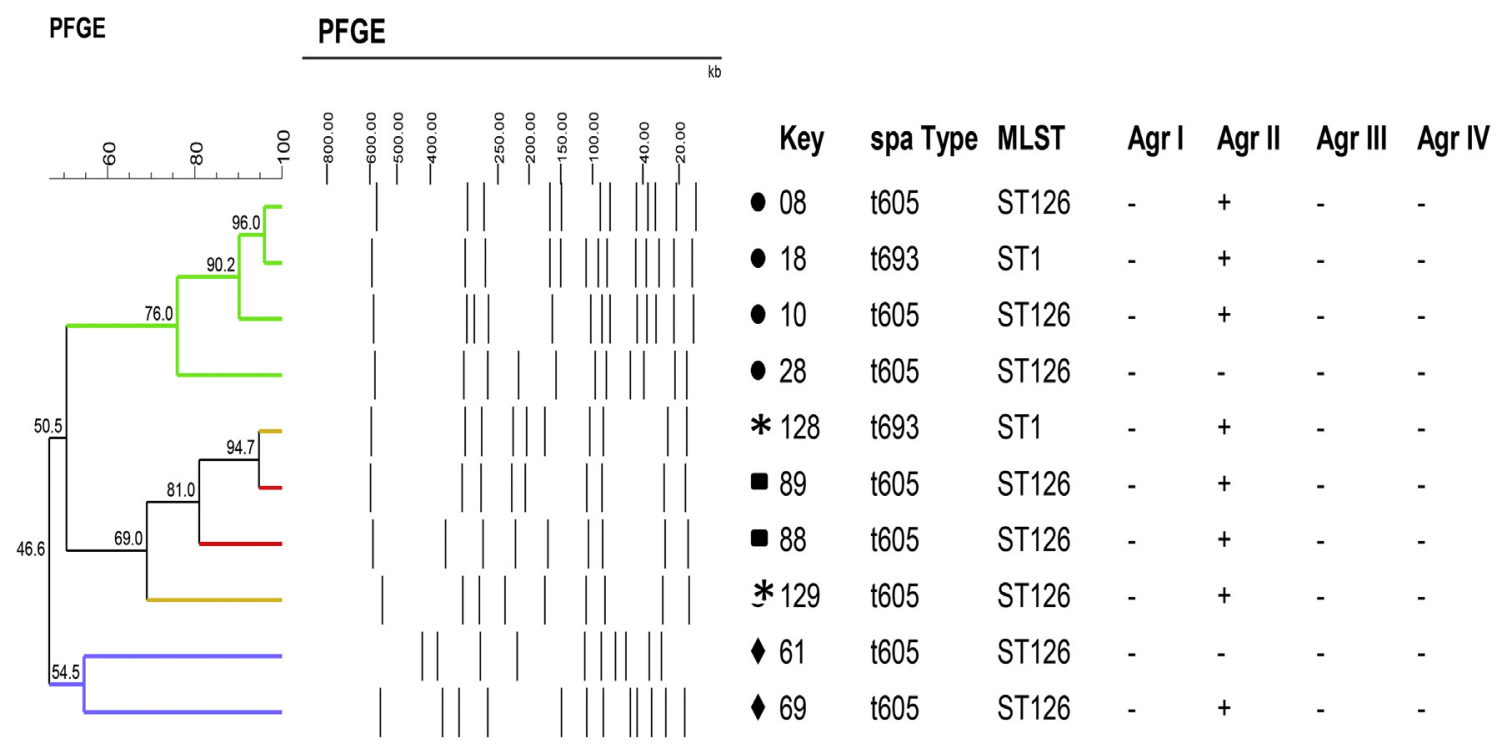

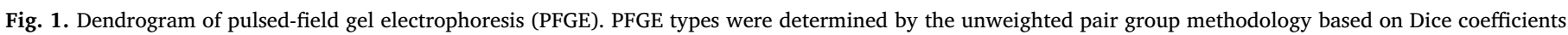

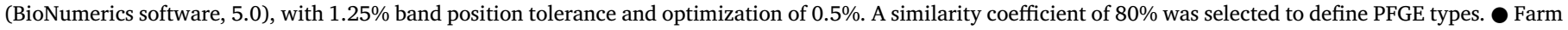
I, * Farm II, • Farm III, $\diamond$ Farm IV. 
isolate each. All 285 strains were sensitive to vancomycin, oxacillin, kanamycin, and gentamicin.

Among the isolates with intermediate resistant to erythromycin $(\mathrm{n}=8$ ), four were positive for the mrsA gene, but the ermA, ermB, and erm $\mathrm{C}$ genes was not noted. All isolates resistant to tetracycline presented with tet(K), while the tet(M) and tet(L) genes was not observed. All three isolates resistant to ciprofloxacin was positive for both the $g r l$ (A) and gyr (A) genes; Sanger sequencing was performed to identify mutations in amino acids, but none were observed. The ant(4') gene, responsible for tobramycin resistance, was identified in intermediate and resistant isolates. The mecA, and mecC genes were not noted in cefoxitin-resistant isolates.

\section{Discussion}

The interest in MSSA has increased in recent years since it may also be involved in important infections and could help to explain the occurrence and development of different successful strains of MRSA. There are few data regarding MSSA genetic strains in food products of animal origin and derivatives such as milk [10].

We found high diversity in spa types $(\mathrm{n}=23)$ in 285 isolates of MSSA associated with subclinical mastitis. Aires-de-Sousa et al. [31] and Silva et al. [10] also reported the prevalence of t605 and t127 in Brazil. Said et al. [32] observed the MSSA spa type t605 in Canada, and t127 has already been found in Switzerland [33] and Korea [34] in isolates from bovine mastitis.

As far as we know, this is the first report of the detection of spa type t321 isolates in milk samples from cows with subclinical mastitis. Previously, it has only been isolated from humans, and swine [35-37], showing that the host specificity of the pathogen may be questioned.

One limitation in this study was related to performing other molecular characterizations only in the most frequent spa types (t605 and t127), this included $81 \%$ of all isolates. MLST characterization was performed, and most of the clones were ST126, corresponding to 70,5\% of the isolates, followed by ST1 (10.5\%), belonging to CC 126 and 1, respectively. The Ridom Staph Type software also identified five strains belonging to CC 30 , but these were spa types t138 $(n=1)$ and $t 318$ $(n=4)$. One strain was identified as t177 belonging to CC1; it is important to note that this CC is most commonly isolated from humans $[38,39]$. The population of $S$. aureus seems to be highly clonal, as suggested by Musser et al. [40]. As noted in other studies [12,41,42], these strains can be represented by several clonal complexes, suggesting that there is no link between the specific genotype of MLST and the propensity to cause disease [43].

In PFGE results, we observed different profiles in isolates within the same spa type. According to Tenover et al. [21], a clone is a group of related isolates belonging to the same PFGE pattern; therefore, strains of the same spa type cannot be called a clone. Also, the presence of the same profiles carrying different molecular markers and virulence genes can explain the difficulty in identifying effective medicines against this pathogen [44]. According to Feil et al. [43], the gain and loss of virulence genes carried out through moving elements play important roles in determining the virulence of an isolate. The movement of these genes can occur so rapidly that the presence or absence is only weakly related to clonal stability.

In summary, we did not find a good correlation between PFGE, spa typing, and MLST and showed that these methods have incomparable discriminatory power. Therefore, we strongly suggest that spa typing can be useful to complement genotyping results in studies to compare bovine mastitis isolates; however, there is no greater specificity when used alone.

One of the most well-known regulatory systems involved in the expression of virulence genes in $S$. aureus is the agr group. Studies have shown that agr type I is more prevalent in humans than in animals [45]. Conversely, agr II has been found more frequently in animals $[10,46,47]$. These results were similar to those of our study, with positivity of $47.7 \%$ for agr II ( $\mathrm{n}=136 / 285$ ), followed by $20 \%$ for type III $(\mathrm{n}=57 / 285)$ and $8.1 \%$ for type I $(\mathrm{n}=23 / 285)$. The presence of $a g r$ type IV was not detected, and 69 (24.2\%) strains were negative for all known types. Melchior et al. [46] suggested that agr type II isolates are better adapted to the dairy environment than agr type I isolates.

Regarding virulence factors, the tsst-1 gene was found in $36.8 \%$ $(105 / 285)$ of isolates, which was similar $(37.5 \%)$ to the result found by Nader Filho et al. [48], also in Brazil. On the other hand, Sá et al. [49] did not observe this gene in $S$. aureus isolated from cows with mastitis from the same region as that investigated in the current study, but their study was performed 13 years ago, which suggests that there may have been a recent diversification of strains or the spread of a new clone into this region, demonstrating the genetic evolution of $S$. aureus towards a more virulent strain.

$S$. aureus strains can encode more than one enterotoxin gene simultaneously; over $50 \%$ of the isolates assessed showed this property [50,51]. In the current study, all 285 strains were positive for at least one gene, and the combination $s e c+s e g+s e h$ was the most frequent, occurring in $56.8 \%$ of isolates. Zschock et al. [50] analyzed milk from cows with mastitis and also observed that some strains of $S$. aureus can encode several genes, with $26.9 \%$ carrying two genes. According to these authors, the simultaneous production of different types of enterotoxins can increase the toxigenic effect, suggesting that this coproduction may play an important role in mastitis. Enterotoxin A (SEA) is one of the most frequently observed enterotoxins [52], although the literature shows highly variable results in the prevalence of $S$. aureus enterotoxin genes, depending on the kind of food and the biovar investigated [53]. In the current study, we found 31 (10.8\%) isolates encoding the sea gene. On the other hand, Hata et al. [54] evaluated this gene in isolates from mastitic milk, which it was not found. As in our study, the $p v l$ gene was not observed by Aires-de-Sousa et al. [31].

The increase in multidrug-resistant $S$. aureus isolated from bovine mastitis is a serious problem, with increasing morbidity and costs related to this disease. In addition, the indiscriminate use of antibiotics can lead to their accumulation in food, which can ultimately affect human health [55]. Since antimicrobial therapy is one of the main tools for the control of mastitis caused by $S$. aureus, antibiogram assays can indicate the best treatment for each case of mastitis [56]. According to our results, $230(80 \%)$ isolates were sensitive to all drugs tested. For the resistant and intermediate strains, we tested the presence of genes responsible for resistance to tetracycline (tetK, tetL, and tet $\mathrm{M}$ ), erythromycin (ermA, ermB, erm $\mathrm{C}$, and $m r s \mathrm{~A}$ ), tobramycin (ant4), and ciprofloxacin $(g l r$, and $g y r)$. The resistance of strains to tetracycline was confirmed by the presence of the tetK gene, and both genes responsible for resistance to ciprofloxacin were present. Regarding the strains with intermediate resistance to erythromycin, only four were positive for the ermA gene and no gene encoding resistance for tobramycin was found. The discrepancy observed between the genotype and phenotype in the four strains with intermediate resistance, which did not harbor any erythromycin resistance genes, was also observed by Goudarzi et al. [57], where nine $S$. aureus isolates were resistant to erythromycin, but did not carry any of the tested erythromycin resistance genes. The authors presumed that other variants of erm genes, the efflux pump $(m s r B)$, and a high rate of horizontal gene transfer were involved in this finding [58-60].

We sequenced both glrA and gyrA (responsible for resistance to ciprofloxacin), which present in three isolates, but no mutations were observed. This resistance could occur due to another mechanism such as the expression or overexpression of efflux pumps that can actively remove antibacterial agents from the cell [61].

The current study clearly shows that only performing molecular profile analyses in $S$. aureus isolated from mastitis is not enough to determine the pathogenic potential, but it did help to obtain insights about the population structure of $S$. aureus in São Paulo State. Due to a wide variety of genotypic profiles, we couldn't describe a predominant profile of $S$. aureus on these farms. Our data suggest that there is no link 
between the virulence and molecular profiles of $S$. aureus associated with mastitis in cows, as highly variable profiles were found.

Additionally, due to the discrepancies observed between the different molecular typing techniques such as PFGE, MLST, and spa typing in the current study, we question the exclusive use of spa typing, since strains with the same type may have no phylogenetic relationship, as shown by PFGE. On the other hand, spa typing can be used for screening purposes, as it is inexpensive, and portable. Moreover, we noted some t321 strains causing bovine mastitis, which had previously been isolated only from pigs and humans.

\section{Conflicts of interest}

All authors of this manuscript have no conflict of interest to declare.

\section{Acknowledgments}

Financial support: Fundação de Amparo à Pesquisa do Estado de São Paulo (FAPESP) Grants 2013/12831-4, and 2013/18338-8.

\section{Appendix A. Supplementary data}

Supplementary data related to this article can be found at https:// doi.org/10.1016/j.micpath.2018.08.031.

\section{References}

[1] M. Bardiau, J. Detilleux, F. Farnir, J.G. Mainil, I. Ote, Associations between properties linked with persistence in a collection of Staphylococcus aureus isolates from bovine mastitis, Vet. Microbiol. 169 (2014) 74-79.

[2] B.B. Asiimwe, R. Baldan, A. Trovato, D.M. Cirillo, Prevalence and molecular characteristics of Staphylococcus aureus, including methicillin resistant strains, isolated from bulk can milk and raw milk products in pastoral communities of South-West Uganda, BMC Infect. Dis. 17 (2017) 422.

[3] Y.H. Park, S.U. Lee, W.A. Ferens, S. Samuels, W.C. Davis, L.K. Fox, J.S.K. AHN, S. Seo, B.S. Chang, S.Y. Hwang, G.A. Bohach, Unique features of bovine lymphocytes exposed to a staphylococcal enterotoxin, J. Vet. Sci. 7 (2006) 233-239.

[4] M. Benic, B. Habrun, G. Kompes, Z. Mihaljevic', Z. Cvetnic', M. Cergolj, N. Macesic, Cell content in milk from cows with ell content in milk from cows with $S$. aureus intramammary infection, Vet. Arch. 82 (2012) 411-422.

[5] E. Rahimi, F. Alian, Presence of enterotoxigenic Staphylococcus aureus in cow, camel, sheep, goat, and buffalo bulk tank milk, Vet. Arch. 83 (2013) 23-30.

[6] P. Kalmus, B. Aasmae, A. Karssin, T. Orro, K. Kask, Udder pathogens and their resistance to antimicrobial agents in dairy cows in Estonia, Acta Vet. Scand. 53 (2011).

[7] T. Jagielski, E. Puacz, A. Lisowski, P. Siedlecki, W. Dudziak, J. Międzobrodzki, H. Krukowski, Antimicrobial susceptibility profiling and genotyping of Staphylococcus aureus isolates from bovine mastitis in Poland, J. Dairy Sci. 97 (2014) 6122-6128.

[8] X. Wang, Y. Wang, G. Guo, T. Usman, D. Hao, X. Tang, Y. Zhang, Y. Yu, Antimicrobial resistance and toxin gene profiles of Staphylococcus aureus strains from Holstein milk, Lett. Appl. Microbiol. 58 (2014) 527-534.

[9] E.M. Smith, L.E. Green, G.F. Medley, H.E. Bird, G. Dowson, Multilocus sequence typing of Staphylococcus aureus isolated from high somatic- cell-count cows and the environment of an organic dairy farm in the United Kingdom, J. Clin. Microbiol. 43 (2005) 4731-4736.

[10] N.C.C. Silva, F.F. Guimaraes, M.P. Manzi, P.E. Budri, E. Gomez-Sanz, D. Benito, H. Langoni, V.L.M. Rall, C. Torres, Molecular characterization and clonal diversity of methicillin-susceptible Staphylococcus aureus in milk of cows with mastitis in Brazil, J. Dairy Sci. 96 (2013) 6856-6862.

[11] R. Zadoks, W. Van Leeuwen, H. Barkema, O. Sampimon, H. Verbrugh, Y.H. Schukken, A. Van Belkum, Application of pulsed-field gel electrophoresis and binary typing as tools in veterinary clinical microbiology and molecular epidemiologic analysis of bovine and human Staphylococcus aureus isolates, J. Clin. Microbiol. 38 (2000) 1931-1939.

[12] U. Nubel, B. Strommenger, F. Layer, W. Witte, From types to trees: reconstructing the spatial spread of Staphylococcus aureus based on DNA variation, Int. J. Med. Microbiol. 301 (2011) 614-618.

[13] O.W. Schalm, D.D. Noorlander, Experiments and observations leading to development of the California Mastitis Test, J. Am. Vet. Med. Assoc. 130 (1957) 199-204.

[14] G.W. Procop, D.L. Church, G.S. Hall, W.M. Janda, E.W. Koneman, P.C. Schreckenberger, G.L. Woods, Koneman's Color Atlas and Textbook of Diagnostic Microbiology, seventh ed., Wolters Kluwer, Philadelphia, 2016.

[15] CRL-AR, Community Reference Laboratory for Antimicrobial Resistance Multiplex PCR for the Detection of the MecA Gene and the Identification of Staphylococcus aureus, National Food Institute. Technical University of Denmark, Copenhagen, 2009.
[16] K. Omoe, M. Ishikama, Y. Shimoda, D.L. Hu, S. Ueda, K. Shinagawa, Detection of seg, seh and sei genes in Staphylococcus aureus isolates and determination of the enterotoxin productivities of $S$. aureus isolates harboring seg, seh or sei genes, J. Clin. Microbiol. 40 (2002) 857-862

[17] S. Jarraud, C. Mougel, J. Thioulouse, G. Lina, H. Meugnier, F. Forey, F. Vandenesch, Relationships between Staphylococcus aureus genetic background, virulence factors, agr groups (Alleles), and human disease, Infect. Immun. 70 (2002) 631-641.

[18] G. Lina, Y. Piémont, F. Godail-Gamot, M. Bes, M.O. Peter, V. Gauduchon, F. Vandenesch, J. Etienne, Involvement of Panton-Valentine leukocidin-producing Staphylococcus aureus in primary skin infections and pneumonia, Clin. Infect. Dis. 29 (1999) 1128-1132.

[19] B. Shopsin, B. Mathema, P. Alcabes, B. Said-Salim, G. Lina, A. Matsuka, J. Martinez, B.N. Kreiswirth, Prevalence of agr specificity groups among Staphylococcus aureus strains colonizing children and their guardians, J. Clin. Microbiol. 41 (2003) 456-459.

[20] L.K. McDougal, C.D. Steward, G.E. Killgore, J.M. Chaitram, S.K. McAllister, F.C. Tenover, Pulsed-field gel electrophoresis typing of oxacillin-resistant Staphylococcus aureus isolates from the United States: establishing a national database, J. Clin. Microbiol. 41 (2003) 5113-5120.

[21] F.C. Tenover, R.D. Arbeit, V.R. Goering, P.A. Mickelsen, B.E. Murray, D.H. Persing, B. Swaminathan, Interpreting chromosomal DNA restriction patterns produced by pulsed-field gel electrophoresis: criteria for bacterial strain typing, J. Clin. Microbiol. 33 (1995) 2233-2239.

[22] CLSI (Clinical Laboratory Standards Institute), Performance Standards for Antimicrobial Susceptibility Testing. Nineteenth Informational Supplement. M100-s19, National Committee for Clinical Laboratory Standards, Wayne, PA 2015.

[23] B. Rojo-Bezares, Y. Sáenz, P. Poeta, M. Zarazaga, F. Ruiz-Larrea, C. Torres, Assessment of antibiotic susceptibility within lactic acid bacteria strains isolated from wine, Int. J. Food Microbiol. 111 (2006) 234-240.

[24] F.J. Schmitz, M. Steiert, H.V. Tichy, B. Hofmann, J. Verhoef, H.P. Heinz, K. Kohrer, M.E. Jones, Typing of methicillin-resistant Staphylococcus aureus isolates from Düsseldorf by six genotypic methods, J. Med. Microbiol. 47 (1998) 341-351.

[25] N.C. Clark, Ø. Olsvik, J.M. Swenson, C.A. Spiegel, F.C. Tenover, Detection of a streptomycin/spectinomycin adenylyl transferase gene (aadA) in Enterococcus faecalis, Antimicrob. Agents Chemother. 43 (1999) 157-160.

[26] F.M. Aarestrup, Y. Agerso, P. Gerner-Smidt, M. Madsen, L.B. Jensen, Comparison of antimicrobial resistance phenotypes and resistance genes in Enterococcus faecalis and Enterococcus faecium from humans in the community, broilers, and pigs in Denmark, Diagn. Microbiol. Infect. Dis. 37 (2000) 127-137.

[27] C. Kehrenberg, S. Schwarz, Florfenicol-chloramphenicol exporter gene fexA is part of the novel transposon Tn558, Antimicrob, Agents Chemother 49 (2005) 813-815.

[28] C. Kehrenberg, S. Schwarz, Distribution of florfenicol resistance genes fexA and cfr among chloramphenicol-resistant Staphylococcus isolates, Antimicrob. Agents Chemother. 50 (2006) 1156-1163.

[29] C. Schnellmann, V. Gerber, A. Rossano, V. Jaquier, Y. Panchaud, M.G. Doherr, A. Thomann, R. Straub, V. Perreten, Presence of new mecA and $m p h(C)$ variants conferring antibiotic resistance in Staphylococcus spp. isolated from the skin of horses before and after clinic admission, J. Clin. Microbiol. 44 (2006) 4444-4454.

[30] Y. Kondo, T. Ito, X.X. Ma, S. Watanabe, B.N. Kreiswirth, J. Etienne, Combination of multiplex PCRs for Staphylococcal Cassette Chromosome mec type assignment: rapid identification system for $m e c, c c r$, and major differences in junkyard regions, Antimicrob. Agents Chemother. 51 (2007) 264-274.

[31] M. Aires-de-Sousa, C. Parente, O. Vieira-da-Motta, I. Bonna, D. Silva, H. Lencastre, Characterization of Staphylococcus aureus isolates from buffalo, bovine, ovine, and caprine milk samples collected in Rio de Janeiro State, Brazil, Appl. Environ. Microbiol. 12 (2007) 3845-3849.

[32] K.B. Said, J. Ismail, J. Campbell, M.R. Mulvey, A.M. Bourgault, S. Messier, X. Zhao, Regional profiling for determination of genotype diversity of mastitis-specific Staphylococcus aureus lineage in Canada by use of clumping factor A, pulsed-field gel electrophoresis, and spa typing, J. Clin. Microbiol. 48 (2010) 375-386.

[33] H. Huber, S. Koller, N. Giezendanner, R. Stephan, C. Zweifel, Prevalence and characteristics of methicillin-resistant Staphylococcus aureus in humans in contact with farm animals, in livestock, and in food of animal origin Switzerland, Euro Surveill. 15 (2010) (2009) pii $=19542$.

[34] S.Y. Hwang, Y.K. Park, H.C. Koo, Y.H. Park, Spa typing and enterotoxin gene profile of Staphylococcus aureus isolated from bovine raw milk in Korea, J. Vet. Sci. 11 (2010) 125-131.

[35] E. Székely, A. Man, A. Mare, K.E. Vas, S. Molnár, D. Bilca, J. Szederjesi, F. Toma, L. Lirinczi, Molecular epidemiology and virulence factors of methicillin-resistant Staphylococcus aureus strains in a Romanian university hospital, Rev. Român. Med. Lab. 20 (2012) 371-382.

[36] E. Huang, A.E. Gurzau, B.M. Hanson, A.E. Kates, T.C. Smith, M.M. Pettigrew, M. Spinu, P.M. Rabinowitz, Detection of livestock-associated methicillin-resistant Staphylococcus aureus among swine workers in Romania, J. Infect. Public Health 4 (2014) 323-332.

[37] C. Locatelli, P. Cremonesi, A. Caprioli, V. Carfora, A. Ianzano, A. Barberio, S. Morandi, P. Moroni, Occurrence of methicillin-resistant Staphylococcus aureus in dairy cattle herds, related swine farms, and humans in contact with herds, J. Dairy Sci. 100 (2017) 608-619.

[38] C. Lozano, A. Rezusta, P. Gómez, E. Gómez-Sanz, N. Báez, G. Martin-Saco, M. Zarazaga, C. Torres, High prevalence of spa types associated with the clonal lineage CC398 among tetracycline-resistant methicillin-resistant Staphylococcus aureus strains in a Spanish hospital, J. Antimicrob. Chemother. 67 (2012) 330-334.

[39] M.A. Argudín, M.C. Mendoza, M.A. González-Hevia, M. Bances, B. Guerrac, M.R. Rodicio, Genotypes, exotoxin gene content, and antimicrobial resistance of 
Staphylococcus aureus strains recovered from foods and food handlers, Appl. Environ. Microbiol. 78 (2012) 2930-2935.

[40] J.M. Musser, M.P. Schlievert, A.W. Chow, P. Ewan, B.N. Kreiswirth, V.T. Rosdahl, A.S. Naidu, W. Witte, R.K. Selander, A single clone of Staphylococcus aureus causes the majority of cases of toxic shock syndrome, Proc. Natl. Acad. Sci. Unit. States Am. 87 (1990) 225-229.

[41] E. Hata, K. Katsuda, H. Kobayashi, T. Ogawa, T. Endo, M. Eguchi, Characteristics and epidemiologic genotyping of Staphylococcus aureus isolates from bovine mastitic milk in Hokkaido, Japan, J. Vet. Med. Sci. 2 (2006) 165-170.

[42] K.Y. Chua, T.P. Stinear, B.P. Howden, Functional genomics of Staphylococcus aureus, Brief Funct. Genomics. 12 (2013) 305-315.

[43] E. Feil, E.J. Cooper, H. Grundmann, D.A. Robinson, M.C. Enright, T. Berendt, S.J. Peacock, J.M. Smith, M. Murphy, B.G. Spratt, C.E. Moore, N.P.J. Day, How clonal is Staphylococcus aureus? J. Bacteriol. 11 (2003) 3307-3316.

[44] E.A.L. Pereyra, S.C. Sacco, A. Duré, C. Baravalle, M.S. Renna, C.S. Andreotti, S. Moneckec, L.F. Calvinho, B.E. Dallard, Immune response of Staphylococcus aureus strains in a mouse mastitis model is linked to adaptive capacity and genotypic profiles, Vet. Microbiol. 204 (2017) 64-76.

[45] W. Van Leeuwen, W. Van Nieuwenhuizen, C. Gijzen, H. Verbrugh, A. Van Belkum, Population studies of methicillin-resistant and -sensitive Staphylococcus aureus strains reveal a lack of variability in the agrD gene encoding a staphylococcal autoinducer peptide, J. Bacteriol. 182 (2000) 5721-5729.

[46] M.B. Melchior, M.H.J. van Osch, R.M. Graat, E. van Duijkeren, D.J. Mevius, M. Nielen, W. Gaastra, J. Fink-Gremmels, Biofilm formation and genotyping of Staphylococcus aureus bovine mastitis isolates: evidence for lack of penicillin-resistance in agr type II strains, Vet. Microbiol. 137 (2009) 83-89.

[47] V.F. Marques, C.C. Motta, B. Soares, D.A. Melo, S.M.O. Coelho, I.S. Coelho, H.S. Barbosa, M.M.S. Souza, Biofilm production and beta-lactamic resistance in brazilian Staphylococcus aureus isolates from bovine mastitis, Braz. J. Microbiol. 48 (2017) 118-124.

[48] A. Nader Filho, L.M. Ferreira, L.A. Amaral, O.D. Rossi Junior, R.P. Oliveira, Production of enterotoxins and toxic shock syndrome toxin by Staphylococcus aureus strains isolated from bovine mastitis, Braz. J. Res. An. Sci. 59 (2007) 1316-1318.

[49] M.E.P. Sá, M.L.R.S. Cunha, A.O. Elias, C. Victória, H. Langoni, Importance of Staphylococcus aureus in bovine subclinical mastitis: presence of enterotoxins, shock syndrome toxin and relationship with somatic cell count, Braz. J. Vet. Res. Anim. 41 (2004) 320-326.

[50] M. Zschöck, B. Kloppert, W. Wolter, H.P. Hamann, C.H. Lammler, Pattern of enterotoxin genes seg, seh, sei and sej positive Staphylococcus aureus isolated from bovine mastitis, Vet. Microbiol. 108 (2005) 243-249.

[51] V. Srinivasan, A.A. Sawant, B.E. Gillespie, S.J. Headrick, L. Ceasaris, S.P. Oliver, Prevalence of enterotoxin and toxic shock syndrome toxin genes in Staphylococcus aureus isolated from milk of cows with mastitis, Foodb. Pathog. Dis. 3 (2006) 274-283.

[52] S.N. Al-Bahry, Y.I. Mahmoud, S.K. Al-Musharafi, N. Sivakumar, Staphylococcus aureus contamination during food preparation, processing and handling, I, Int. J. Chem. Eng. Appl. 5 (2014) 5.

[53] A. Normanno, Firinu, S. Virgilio, G. Mula, A. Dambrosio, A. Poggiu, L. Decastelli, R. Mioni, S. Scuota, G. Bolzoni, E. Di Giannatale, A.P. Salinetti, G. La Salandra, M. Bartoli, F. Zuccon, T. Pirino, S. Sias, A. Parisi, N.C. Quaglia, G.V. Celano, Coagulase-positive Staphylococci and Staphylococcus aureus in foods products marketed in Italy, Food Microbiol. 98 (2005) 73-79.

[54] E. Hata, K. Katsuda, H. Kobayashi, I. Uchida, K. Tanaka, M. Eguchi, Genetic variation among Staphylococcus aureus strains from bovine milk and their relevance to methicillin-resistant isolates from humans, J. Clin. Microbiol. 48 (2010) 2130-2139.

[55] M. Pol, P.L. Ruegg, Relationship between antimicrobial drug usage and antimicrobial susceptibility of Gram-positive mastitis pathogens, J. Dairy Sci. 90 (2007) 262-273.

[56] P. Moroni, G. Pisoni, M. Antonini, R. Villa, P. Boettcher, S. Carli, Antimicrobial drug susceptibility of Staphylococcus aureus from subclinical bovine mastitis in Italy, J. Dairy Sci. 89 (2006) 2973-2976.

[57] G. Goudarzi, F. Tahmasbi, K. Anbari, M. Ghafarzadeh, Distribution of genes encoding resistance to macrolides among Staphylococci isolated from the nasal cavity of hospital employees in Khorramabad, Iran, Iran. Red Crescent Med. J. 18 (2016) 25701.

[58] R.M. Paiva, A.B.M.P. Machado, A.P. Zavascki, A.L. Barth, Vancomycin MIC for methicillin-resistant coagulase-negative Staphylococcus isolates: evaluation of the broth microdilution and Etest methods, J. Clin. Microbiol. 48 (2010) 4652-4654.

[59] S. Abdollahi, R. Ramazanzadeh, Z. Delami Khiabani, E. Kalantar, S. Menbari, Molecular detection of inducible clindamycin resistance among staphylococca strains isolated from hospital patients, in: Persian (Ed.), J. Ardabil. Uni. Med Sci. 1 (2013) 59-68.

[60] S.R. Kareen, S.S. Al- Jubori, M. Ali, Prevalence of erm genes among methicillin resistant Staphylococcus aureus MRSA Iraqi isolates, Int. J. Cur. Microbiol. App. Sci. 5 (2015) 575-585.

[61] D.C. Hooper, Mechanisms of action and resistance of older and newer fluoroquinolones, Clin. Infect. Dis. 31 (2000) S24-8. 